\section{CRISIS DE LA MODERNIDAD. EL ESCENARIO DEL SIGLO XX}

\author{
José Lasaga \\ Fundación José Ortega y Gasset \\ Madrid
}

\section{CRISIS OF MODERNITY. THE SCENARIO OF THE TWENTIETH CENTURY}

\begin{abstract}
Hannah Arendt identifies the end of modernity with the emergence of the totalitarian systems. They represent the failure of a dangerous life style, that of the animal laborans, in which modernity crystallizes, and which leads to the ruin of the public sphere. Totalitarianism is a consequence of the loss of meaning that fermented in the forgetting of political action, during the transition from the 17th to the 19th century, with the restoration of a metaphysical thinking interested in sacrificing the weakness of meaning that is born out of action to an interpretation of History as a totality well built by Reason.
\end{abstract}

KEY WORDS: Arendt; modernity; totalitarianism; banality of evil; political action; mass.

\section{1}

La crisis de la modernidad, según Arendt, se ha resuelto. Entendido el término en su sentido historiográfico, como el período temporal que arranca de otra crisis, la del mundo medieval que culmina con el surgimiento de la subjetividad cartesiana y la objetividad de la ciencia físico-matemática, habría llegado a su fin con el ciclo de grandes guerras europeas de 1914 a 1945. Las formas culturales más características que nacieron con la nueva época, al filo del siglo XVII, se han agotado y perdido su razón de ser: la nación-estado y su estilo de hacer política (raison d'état); la visión del mundo burgués, cifrada en una filosofía de la historia que hace del progreso su ideal supremo y su motor, y lo humano como "valor" alternativo a lo divino trascendente, anclado en una concepción optimista de la naturaleza humana; finalmente, hasta la ciencia misma y su concepto de verdad se habrian convertido en "otra cosa" que muy pocos habian intuido antes del final del siglo $X X$, y que ahora llamamos, entre otros, con el nombre de "tecno-ciencia".

Lo que demuestra de manera inequivoca el fin de la modernidad, bajo la especie de desastre o naufragio histórico,
RESUMEN: Hannah Arendt identifica el fin de la modernidad con el surgimiento de los sistemas totalitarios. Estos representan el fracaso de un estilo de vida peligroso, el del animal laborans, en el que cristaliza la modernidad y que conduce a la ruina del espacio público. El totalitarismo es una consecuencia de la pérdida de sentido que fermentó en el olvido de la acción política que se gestó en el tránsito del siglo XVII al XIX, con la restauración de un pensar metafísico interesado en sacrificar la debilidad del sentido que nace de la acción a una interpretación de la Historia como una totalidad bien edificada por la Razón.

PALABRAS CLAVE: Arendt; modernidad; totalitarismo; banalidad del mal; acción política; masa.

incluso bajo la especie de "fin de la historia", es para Arendt el surgimiento de los sistemas totalitarios.

El libro que escribió para comprender lo que había sucedido en Europa desde que la Unión Soviética cayó bajo el dominio de Stalin -cosa que sitúa en 1929- y Alemania bajo el de Hitler, en 1933, lo redactó en EEUU entre 1945 y 1949. Es importante para nuestro propósito ${ }^{1}$ recordar cómo vio Arendt la experiencia totalitaria con una cierta distancia y con muchos más conocimientos sobre el funcionamiento de los mecanismos totalitarios. En 1966, con motivo de una nueva edición, añadió un prólogo específico para la tercera parte, titulada precisamente "Totalitarismo". Parecía que aquella experiencia "política" en absoluto semejante a cualquiera de las formas de Estado que se conocían desde los tiempos más antiguos, había concluido. Hitler había sido derrotado en 1945 y la muerte de Stalin en 1953 había desbloqueado la evolución del régimen soviético hacia una dictadura de partido único cualitativamente distinta, como forma política, de la gestalt totalitaria. El recuerdo, más de veinte años después, de lo que había pasado en su Europa natal en el período que antecedió a la redacción de Los orígenes del totalitarismo (OT), evocaba aún un paisaje notablemente descorazonador de 
"décadas de desorden, confusión y horror -las revoluciones tras la primera guerra mundial, la ascensión de los movimientos totalitarios y el debilitamiento del Gobierno parlamentario, seguidos por toda clase de nuevas tiranías, fascistas y semifascistas, dictaduras de partido único y militares $y$, finalmente, el aparentemente firme establecimiento de Gobiernos totalitarios que descansaban en el apoyo de las masas" (OT, 27)

Pero todo eso había pasado y la historia se había tomado un respiro. El triunfo felizmente transitorio del totalitarismo permitió comprender que la modernidad y sus alucinaciones habian terminado. El éxito del animal laborans ${ }^{2}$ -entiéndase como un estilo de vida- se había revelado como peligroso y su forma de hacer política inaceptable. El primer intento de convertir el mundo, y con él todas las instituciones que dan estabilidad a la vida humana, en un proceso $\sin$ fin en donde todo se consume había fracasado al desaparecer los dos sistemas totalitarios. $Y$ aunque en el futuro podía regresar bajo otras configuraciones, la evolución de los acontecimientos abría un espacio para la reflexión o como Arendt prefiere decir, para la comprensión. Pero la lección que ella sacaba de todo esto no era ni mucho menos desoladora o nostálgica. Más bien acierta Ricoeur al calificarla como una "resistente" ${ }^{3}$. Y la prueba más clara de este carácter de resistente se halla en el esfuerzo teórico que hizo a lo largo de toda su obra por hallar una interpretación de la realidad acaecida que le permitiera sobrepasar las inevitables emociones tristes que se seguian de tanto desastre y reconciliarse con el mundo 4 .

Finalmente lo logró, cuando estuvo en condiciones de reinterpretar lo ocurrido a los judios, el programa de la "solución final", la deportación en masa de los judíos europeos hacia las "fábricas de la muerte" ${ }^{5}$, no en términos de "mal radical" sino como mal "banal". El giro conceptual, que tuvo enormes implicaciones biográficas y teóricas, se originó en las reflexiones que llevó a cabo para redactar las crónicas sobre el juicio de Eichmann ante un tribunal del Estado de Israel en 1961. El mal radical es demoníaco y, en condición de tal, trasciende la responsabilidad humana ${ }^{6} .0$ hay algo corrompido en la "naturaleza" humana tal y como el actor individual se encuentra encarnado en ella para decidir su vida; o el mal es de factura humana y cae dentro del campo de sentido que abren las acciones libres de los nacidos. En este caso, ¿cómo pensar el mal que había generado el nazismo al proponerse la liquidación planificada de un pueblo? El problema era dar con conceptos capaces de aprehender las no-cualidades de los hombres y situaciones que lo habían hecho posible ${ }^{7}$. Y eso fue lo que se le reveló a Arendt escuchando y viendo gesticular a aquel hombrecillo que había organizado la deportación de millones de seres humanos desde las ciudades y pueblos de media Europa en dirección a sus confines del este. Eichmann podía ser "culto" pero carecía de capacidad de juicio: era incapaz de sopesar lo que estaba bien y lo que estaba mal. Y ahí residia el fatal origen de su capacidad para convertirse en agente de un mal, que, estando más cerca de la capacidad de propagarse como un hongo por cualquier superficie, que de la gesticulación satánica de quien le planta cara al Bien, convenía que fuera descrito como "banal"8.

Independientemente de la cantidad de malentendidos que provocara el uso del término "banalidad" y el general el tratamiento que Arendt dio al "Holocausto", ella misma se tomó su descubrimiento muy en serio. Tanto, que puede decirse que orientó el resto de sus trabajos en una precisa dirección que le empujaba de nuevo hacia las cuestiones que habian originado sus grandes libros. Si OT había aspirado a responder a las preguntas ¿qué pasó, por qué pasó; cómo pudo pasar?, la $\mathrm{CH}$ partía de la tercera, que no había sido respondida a satisfacción. Cuando el libro estuvo terminado y el "cómo" respondido mediante la tesis de que la modernidad habia puesto en marcha un conjunto de transformaciones que había terminado en lo que llamó metafóricamente "el triunfo del animal laborans"9 y la destrucción del mundo, Arendt creyó que no había acertado con el planteamiento. Había descrito los quehaceres de la "vita activa" desde el punto de vista de "vita contemplativa"10. El hiato abierto entre comprensión y acción por el problema de cómo había surgido una figurada "política" que producía el "mal radical", le impedía, por un lado, articular, aun en la diferencia, las dos cosas que más le habían importado, la filosofía y la política, y, por otra, explicar los dos supuestos antropológicos que operaban como puente entre la acción humana y el mundo: la voluntad y la capacidad de juzgar. De ahí que proyectara y escribiera, La vida del espíritu, dividida en tres partes, dedicadas respectivamente al pensamiento, la voluntad y el juicio. Era un esfuerzo más por aclarar qué capacidades humanas enfermaban cuando en una sociedad emergían hombres capaces de poner en marcha actividades radicalmente perversas, pero de cuyo mal apenas eran conscientes porque la banalidad de su 
carácter los convertía en seres incapaces de juicio $y_{\text {, por }}$ tanto, en agentes de propagación del mal. En otras palabras, Arendt buscó en la vida del espíritu el "fundamento" para su teoría sobre el mal ${ }^{11}$.

Forzando el alcance de algunas obras menores, se podría decir que todos sus libros estuvieron dedicados a profundizar en la tarea ya comenzada en el primero de su obra madura, de comprender lo que desafía toda comprensión: cómo había sido posible la matanza planificada técnicamente de todo un pueblo, el judio, en una de las naciones europeas más cultas y desarrolladas y sus secuelas en todos los órdenes de la vida, en el público, en el cultural y hasta en el íntimo.

\section{2}

Arendt nunca prestó mucha atención a la cuestión del método de conocimiento. Más bien despreció ese tipo de cuestiones tan caras a la academia. Ocupó plaza de "outsider" en las grandes instituciones universitarias que la acogieron. Pero como pensadora conscientemente perspectivista, Arendt se cuida de decirle al lector dónde hinca su mirada: lo hace desde la cofa de un barco que se está hundiendo. La metáfora es de Walter Benjamin ${ }^{12}$. Arendt la asocia con otra de Kafka en la que éste observa que mientras uno lucha contra la desesperación puede tomar notas sobre lo que pasa en medio de las ruinas. También fue Kafka quien le proporcionó la idea de que la modernidad vivió de una perspectiva: la del punto de vista de Arquímedes que contemplaba el universo desde un enclave imaginario exterior al mismo, lo que permitía al observador concebir la naturaleza como un todo y sus cambios como partes de un proceso único ${ }^{13}$.

Arendt, instalada sobre el mástil del navío que se hunde, fue una crítica no sé si más o menos radical que otros contemporáneos cercanos. Heidegger miró la modernidad desde una distancia tan confortable como la de Arquímedes, aunque el observatorio se Ilamó "diferencia ontológica". Arendt lo critica encubiertamente cuando habla del giro que tuvieron que dar algunos hacia el pensamiento puro después de haberse llevado un fiasco al intervenir en el campo político ${ }^{14}$. Adorno y Horkheimer dependieron demasiado de la vieja metafísica hegeliana, cuyo sentido había sido destruido desde la ciencia que ellos criticaban ${ }^{15}$. Eran ilustrados a su pesar porque la pulsión utópica, que nunca abandonaron, les impedía abandonar el observatorio privilegiado que comparten con la ciencia aquellos que siguen creyendo que la historia se hace como se hace un barco o una casa ${ }^{16}$. No obstante, su profunda veracidad intelectual les llevó a reconocer las aporias en que se habian sumergido al extraer de sus críticas a la llustración la identificación entre razón y dominio y postular como única "salvación" la reconciliación del hombre con la naturaleza, sin que llegara a estar claro en términos prácticos que significaba eso ${ }^{17}$. La prueba de que se mantuvieron en el orden de las viejas categorías de pensamiento reside en que fueron eficaces con la crítica pero no hallaron el camino hacia la reconciliación y el amor mundi, única señal fiable de que se ha comprendido.

\section{3}

Tal y como hemos dicho en el apartado primero, la modernidad termina cuando la sociedad europea de los estadosnación ha puesto en marcha los procesos económicos, políticos e históricos que destruirán el soporte material y espiritual de la forma de vida europea. El éxito del totalitarismo en Alemania y su contaminación al resto de Europa es el acontecimiento que ilumina ese proceso de destrucción que Arendt persigue hasta sus orígenes en la nuova scienza, la sociedad ilustrada, el idealismo historicista, el utilitarismo, los fenómenos del imperialismo y la revolución industrial.

La metáfora adecuada al siglo XX es "tiempos de oscuridad". La manera en que lo describe en el primer artículo de Hombres en tiempos de oscuridad nos pone en la pista del alcance que da a la metáfora "tiempos de oscuridad", aquéllos en los que ha tenido lugar la destrucción del "ámbito de lo público", la oclusión de la política. Para quien no esté familiarizado con el pensamiento de Arendt hay que apresurarse a señalar que el ámbito de lo público es el correlato de la acción, del mismo modo que la vida lo es de la labor y el mundo de artefactos duraderos (cosas e ingenios) lo es del trabajo ${ }^{18}$. Lo que da sentido a la vida humana, más allá de su realidad biológica, es, por un lado, el trabajo, pero sobre todo la experiencia de libertad espontánea y creación que tiene lugar en el espacio de lo 
público. Por lo demás, sólo en la acción política se genera sentido, de modo que el mundo como tal y las claves para su comprensión depende de las acciones humanas en el espacio de aparición y de las subsecuentes narraciones que dan cuenta de ellas. El homo faber y el animal laborans no entienden la acción política y argumentan que lo más decisivo son los valores que dominan sus respectivas esferas de existencia, pero no pueden "prescindir por completo de la esfera pública, ya que sin un espacio de aparición y sin confiar en la acción y el discurso como modo de estar juntos, ni la realidad del yo de uno ni la realidad del mundo circundante pueden establecerse fuera de toda duda" $(\mathrm{CH}$, 274). A pesar de las dificultades de la traducción, es claro que Arendt afirma nítidamente que el mundo, en cuanto realidad extramental, es una función de la esfera pública y de las actividades que en ella tienen lugar ${ }^{19}$. Discutir la tesis a fondo nos llevaria muy lejos. De ella nos importa ahora únicamente la implicación que contiene respecto del análisis de la crisis de la modernidad que propone Arendt. Pues, la pérdida -en el sentido de enajenación, incluso de perversión- del espacio público es para Arendt, ya lo hemos dicho, la grieta que arruina la Modernidad. No la economía, no la decadencia de las formas culturales y la "crisis de fundamentos" de la filosofía y de la ciencia, no las contradicciones de la civilización o su dejación moral, sino la definitiva cerrazón de ese espacio público al que, en algunas ocasiones históricas, los hombres concurren en condiciones de igualdad para tomar decisiones.

La posibilidad de que la crisis del Renacimiento, que ponía fin al mundo cristiano-medieval, permitiera hacer la experiencia de un espacio público, tal y como lo habian conocido los antiguos -la polis griega y la civitas romana-, se dio cuando se produjo el repentino y sorprendente "surgimiento de lo secular" $(H I, 53)$ que coincide con la aparición del nuevo modelo de racionalidad concebido por Descartes y Galileo. La pérdida de prestigio del punto de vista de la contemplación y de la administración religiosa de poder político, basada en el uso coercitivo del miedo al infierno, permitió que poco a poco la política recuperara "para la existencia de los hombres la importancia decisiva y grave que, desde la antigüedad, estaba ausente" (HI, 54). Maquiavelo, los teóricos ingleses de XVII como Locke y Hume y los ilustrados del XVIII, sobre todo Montesquieu, recuperaron en sus reflexiones parte de las vivencias políticas de la antigüedad grecorromana. El cambio se debió a que la secularización del mundo significaba ante todo que el hombre se veía de nuevo como mortal y finito. Arendt deriva el concepto moderno de historia precisamente de esta experiencia de recuperar la conciencia de la finitud en lo humano; de tener que vivir en el horizonte de la contingencia. Y propone un atractivo argumento. EI hombre moderno necesitó, confrontado con el dato de su propia contingencia, hallar alguna figura de inmortalidad cismundana. Así como la polis había sido ese escenario de inmortalidad para el hombre antiguo, así la historia se convirtió en el ámbito en que el hombre podía esperar reconocimiento de sus semejantes:

"la historia, al extenderse en la doble infinitud del pasado y del futuro, puede garantizar la inmortalidad en la tierra de una manera muy similar a como la polis griega o la república romana habian garantizado que la vida y las gestas humanas, en la medida en que revelaban algo esencial y grande, recibirían una permanencia estrictamente humana y terrenal en este mundo" (HI, 58).

A este descubrimiento de la historia como el lugar propio de los humanos -así como la naturaleza lo es para animales y plantas ${ }^{20}$ - debería haber correspondido una filosofía de la acción, esto es, una filosofía política. Y Arendt observa que se intentó. Fue la filosofía que desarrollaron los empiristas ingleses de Hobbes a Hume ${ }^{21}$, quienes, deseosos de "orientarse a sí mismos de acuerdo con las exigencias del ámbito público" (HI. 60), rechazaron el punto de vista contemplativo -esto es metafísico que predominaba aún- para la filosofía que se proponían hacer. Pero los empiristas ingleses no tuvieron suerte en el continente a pesar de haber sido muy leídos por la primera ilustración francesa. Montesquieu recogerá su legado y dará forma a la experiencia política de la modernidad. Es posible que su influencia se desvaneciera cuando la revolución se radicalizó. El significado político de Montesquieu ${ }^{22}$ reside para Arendt en su compresión de la necesidad de someter la esfera del poder a la pluralidad de opiniones ${ }^{23}$.

Podemos establecer casi con la precisión del año, el momento en que la época moderna extravía su camino, al menos en el ámbito de sus teorías. Curiosamente es Kant quien, por influencia de Rousseau, da el giro desde una filosofía cuya tarea es pensar la historia desde la lógica de la acción, a la de una filosofía de la historia que vuelve a concebirse con criterios exclusivamente contemplativos. Y Hegel quien consagra el modelo de una filosofía de la his- 
toria en el que la acción -en el sentido arendtiano- pierde su sentido y la política su propia sustancia, transformada en el proyecto utópico que elabora la razón contemplativa de espaldas al mundo, y la inmortalidad, cuya persecución debía ser el contenido de la historia (las gestas heroicas), deja de ser el atributo de sujetos individuales para ser la especie -la Sociedad, la Humanidad-, a quien corresponde disfrutar la perdurabilidad. La primera alternativa moderna a la metafísica tradicional de corte aristotélico-escolástico no fue la filosofía de la historia idealista, sino la filosofia política de los empiristas ingleses, extraviada en Francia por la "voluntad general" de Rousseau.

Da la impresión de que Arendt sugiere un cierto paralelismo entre Kant y Platón. Éste fue incapaz de comprender que la acción no puede aceptar más criterio de sentido que la persuasión, la pluralidad de razones y argumentos que los hombres libres intercambian entre sí. El orden político no se construye como una casa o un barco. Si se hace, entonces se introduce en la polis el elemento de la coacción y la violencia, que destruye la espontaneidad del libre actuar. El déficit de espacio público padecido por la historia europea y la mala prensa de que siempre ha disfrutado entre los filósofos -habría que decir, hasta que se hicieron "revolucionarios" en el siglo XX- es responsabilidad de Platón y de su esfuerzo por resolver la enemistad entre la filosofía y la polis a raíz de la ejecución de Sócrates ${ }^{24}$.

Del mismo modo, Kant habría sido incapaz de comprender la historia, esa insensata "mezcla de error y violencia" (según palabras de Goethe - HI 65) en lo que ésta tenía de escenario de la acción, por tanto, algo inevitablemente condenado a romper los dictámenes de la razón práctica. El espectáculo de la "falta de sentido del curso de los asuntos humanos" y de la absoluta contingencia en que estos se desenvuelven, no parecía dejarle al filósofo más que una salida: suponer que el sentido de esos acontecimientos había que buscarlo más allá de ellos, en alguna forma de trascendencia. Fue Kant, antes que Hegel, quien recuperó la concepción platónico-agustiniana de la historia, basada en que un Dios es la medida y el Autor ${ }^{25}$ de los acontecimientos humanos, aunque la fórmula es del segundo: la historia está dirigida por la astucia de la razón (cf. HI 65).

Aunque Arendt no lo afirma expresamente pudiera ser que el relativo fracaso de la Revolución Francesa por el triunfo de los demagogos y la implantación del terror condicionara que los filósofos dejaran de confiar en la política. Lo que se palpaba en la superficie de los sucesos era su fragilidad, contingencia y aparente falta de sentido. Con tales experiencias no era posible hallar una "explicación" coherente de la historia que fuera capaz de dar razones sobre los sucedidos, excepto remitiendo éstos a un sentido y un cumplimiento en un final de proceso que tendría lugar en un futuro indeterminado, aunque lógicamente prefigurado. Por tanto la filosofía de la historia al concebirse desde un punto de vista idealista, no podía por definición, comprender la acción humana más que recurriendo a expedientes como el que acabamos de describir, llámese Providencia, Espiritu o Proletariado.

\section{4}

Arendt sitúa el origen de su personal versión del estado de nihilismo que se inicia en Europa a mediados del XIX y que caracteriza las postrimerias de la época moderna en la filosofía de la historia romántica. No el agotamiento del platonismo como fuente de valor y la "muerte de Dios" diagnosticados por Nietzsche, sino la oclusión de la historia como espacio para que los hombres hicieran política y encontraran así una alternativa en el deseo de inmortalidad a la finitud y contingencia que el cristianismo habia universalizado. El nihilismo no consiste tanto en la pérdida de valor, como en la destrucción de las fuentes de sentido. Las dos mejores cabezas políticas de la segunda mitad del XIX, Tocqueville y Marx, confirmaron con su obra el callejón sin salida en el que iba a terminar la modernidad por el regreso de la metafísica. El primero, reconociendo que ya no es posible comprender lo que estaba pasando en la política ${ }^{26}$; y Marx interpretando la acción desde el modelo de la fabricación. Marx interpretó la acción, que hace la historia, desde la fabricación, la experiencia mundana del "homo faber". Volvía así a Platón, aunque secularizado: los hombres que se daban a sí mismos los fines que habían descubierto como valiosos y necesarios de acuerdo con las leyes económicas del materialismo histórico. Las filosofías de la historia, la hegeliana o la marxiana, eran los relatos que intentaban la reconciliación con el mundo al transformar la masa de fracasos, muerte y dolor en un proceso que tuviera sentido por sí mismo ${ }^{27}$. Esta fórmula que buscaba salvar los detalles por su remisión a la totalidad, 
ha fracasado. Como fracasó la variante utilitarista, más cercana a la realidad empírica, de construir la realidad y su significado como el artesano fabrica sus objetos.

Pero el problema de comprender la historia como un proceso sin fin se podia complicar más aún al advertir que la ciencia física había hecho lo mismo con la naturaleza. El ensayo sobre la concepción moderna de la historia arrancaba de la constatación de que lo que diferencia lo moderno de cualquier otra época es concebir la naturaleza y la historia como proceso. En CH, la obra en que Arendt retomará estos análisis a otro nivel de profundidad, asociará el proceso con la labor, que se caracteriza por ser la actividad humana que responde a la necesidad biológica y corporal; en su carácter cíclico, está destinada a recomenzar siempre, $\sin$ fin, en el proceso de la vida que se reproduce a sí misma. Pero el único sentido que tiene el proceso de la vida es el consumo de lo necesario que simplemente la sostiene y reproduce. Algo tiene que romper -y así ocurrió en la antigüedad- ese ciclo para que surja un mundo estable y con él las preguntas que los hombres se hacen acerca de la razón de ser de su estancia sobre la tierra. Ese algo fue la libertad estructurada en espacio público ${ }^{28}$.

Lo que Arendt parece sugerir es que al final de la modernidad estamos en el mismo punto del que surgió la historia europea: en la barbarie previa a la fundación de la polis ${ }^{29}$. Y en la medida en que identifiquemos lo que vino después del nihilismo cultural (de la destrucción del sentido), con las formaciones totalitarias en que se resolvió la intervención del hombre-masa en política, concluiremos que hace algo más que sugerirlo.

- ¿Es el totalitarismo una consecuencia de la pérdida de sentido que fermentó en el olvido de la acción política que se gestó en el tránsito del siglo XVIII al XIX, con la restauración de un pensar metafísico interesado en sacrificar la debilidad del sentido que nace de la acción a una interpretación de la Historia como una totalidad bien edificada por la Razón?

- Sí, en la medida en que convengamos que esto es sólo una parte de un fenómeno más profundo, que Arendt llama de "alienación del mundo" ${ }^{30}$.

El proceso de "explicación" de la historia comienza a parecerse peligrosamente al de explicación de la naturaleza que la ciencia, con ayuda de la técnica, ha alcanzado a lo largo de la época moderna y gracias a haber adoptado el punto de vista de Arquímedes, tal y como comentamos más arriba. La implicación epistemológica del uso científico de la matemática para cuantificar y del experimento para imponer modelos a la naturaleza, reside en que las hipótesis ya no se prueban recurriendo a procedimientos objetivos e independientes, sino que se puede intervenir en el proceso "a partir de ellas", produciendo "una serie de resultados dentro de la realidad que tienen sentido y además, funcionan" (EPF, 97). Lo grave no se advierte hasta que se extrae una consecuencia lógica inserta en la afirmación: si se puede tomar una hipótesis absurda, propia de la más ridícula e increible propaganda de masas, por ejemplo que la salud espiritual y económica de la nación alemana mejorará cuando los judíos sean exterminados, nos podemos encontrar con que la falta de principios en el juego del razonamiento conduzca a que todo sea posible ${ }^{31}$.

Pero que "todo es posible" es el principio que articula la esencia del totalitarismo que, en última instancia, no es sino el salto desde el nihilismo moral del "todo está permitido" -porque Dios ha muerto-, al "todo es posible" porque la realidad mundana, bajo las formas de Naturaleza e Historia, ha desaparecido transmutada en un proceso sin fin carente de sentido. La naturaleza y la historia fueron, algún dia, entidades que se tenían por trascendentes, antes de que la ciencia galileana y la filosofía de la historia hegeliano-marxiana las convirtieran respectivamente en procesos ilimitados a la espera de una ley o de un final, quedando así inutilizadas como soportes mundanos para las acciones de los hombres, horizontes de sentido desde lo que fuera posible esperar alguna forma de verdad trascendente.

Pero ese proceso que parecía pertenecer a la estructura interna de la naturaleza según la moderna ciencia físicomatemática o de la historia, según las filosofías de la historia, pertenece, según Arendt a un tipo humano, el animal laborans, que en un último giro de la historia universal europea se ha convertido en su sujeto único.

Después del fracaso de la vita activa y de su subsunción bajo el punto de vista de la vita contemplativa; después de que el homo faber recuperara cierta iniciativa y desprestigiara la contemplación en los orígenes de la época moderna, gracias a la revalorización del trabajo manual, 
inseparable del lugar que el experimento pasó a ocupar en la ciencia natural, éste, sin embargo, perdió su ganancia muy pronto. Y fue la técnica, incrustada en el corazón del método de la ciencia -la fase de la misma que Ortega ha caracterizado acertadamente como la "técnica del técni$\mathrm{CO}^{132}$-, una vez puesta en marcha la revolución industrial, la que transformó a su vez el mundo de objetos duraderos que es propio del hombre fabricante por cosas listas para ser consumidas y lo que provocó su desprestigio. Además de los procesos económicos que socavaron el valor de uso introduciendo el principio de intercambiabilidad, y la ruina de los demás valores,... "fue decisivo que el hombre comenzara a considerarse parte integrante de los dos procesos sobrehumanos que lo abarcan todo, de la naturaleza y de la historia, los cuales parecian destinados a un infinito progreso", por tanto sin que se dibujara en el horizonte el telos que prometía el sentido o la Idea que armonizaba y daba coherencia a todas las certezas provisionales $(\mathrm{CH}, 401)$.

El mundo y con él la historia se convirtió en un proceso. El industrialismo de la segunda mitad del XIX comenzó a producir mercancias superfluas, restándole al objeto fabricado el carácter de firmeza y duración que había sido capaz de poner, entre el hombre contingente y la naturaleza en devenir, la solidez de un mundo. Y con las mercancías destinadas a ser consumidas en un proceso sin fin, surgieron los hombres superfluos que hicieron posible el fenómeno del imperialismo $0^{33}$ y su consecuencia: la destrucción de la moralidad burguesa y el sistema político que la modernidad había inventado para organizar la convivencia: el estado-nación. Así como la moralidad pública se disolvió en un nihilismo práctico cuando los "hombres superfluos" volvieron de la colonia a la metrópoli habiendo hecho la experiencia de vivir sin principios morales, así las filosofías de la historia estaban preparadas para degenerar en ideologías y el artefacto político inventado por la modernidad -el Estado-nación- listo para ser sustituido por el Estado totalitario, de tal modo que el principio constitucional, fuente de estabilidad y seguridad, fue desplazado por el principio legislativo supremo y único de la voluntad del Führer ${ }^{34}$.

Estaría reservado al siglo XX ver el triunfo de las ideologías sobre el sentido común, al que, por suerte, aún hay que persuadir de la verdad y oportunidad de una determinada propuesta. El darwinismo y el marxismo ofrecerían la materia bruta para las dos únicas cosmovisiones que triunfaron ocupando la conciencia de grandes sectores sociales estruc- turados en movimientos totalitarios. Pero para que ello fuera posible tenían que surgir las masas, esto es, tenían que transformarse los hombres en individuos atomizados y empujados unos contra otros hasta ignorar sus propios intereses y ser incapaces de luchar por los mismos (Cf., EPF, 99-100).

Aunque Arendt no subraya el paralelismo es tentador establecerlo. Así como una filosofía de la historia explica y ordena los acontecimientos históricos, así una ideología reduce la multiplicidad del mundo y la complejidad de las experiencias a un único principio que lo hace todo transparente. Pues lo propio de una ideología, a diferencia de una opinión, señala Arendt, es que afirma poseer "o bien la clave de la Historia o bien la solución de todos los 'enigmas del Universo' o el íntimo conocimiento de las leyes universales ocultas de las que se supone que gobiernan a la Naturaleza y al hombre" (OT, 222).

Para que las ideologías se transformaran en formas efectivas de intervención política tenía que surgir el sujeto adecuado a su mensaje:

"Los movimientos totalitarios son posibles alli donde existen masas que, por una u otra razón han adquirido el apetito de la organización política" (OT, 392)

En el siglo XIX las ideologías todavía no eran eficaces. Sólo llegarian a serlo cuando estallara, en forma de guerras y errores de gobierno, la crisis de la civilización europea, cuando se objetivara en la Gran Guerra de 1914 y se hicieran sentir sus efectos devastadores en todos los órdenes de la existencia. Fue su criatura el surgimiento de una nueva forma de organización política que nadie había podido prever y a la que Arendt bautizó con el término "totalitarismo".

El siglo XX es un nuevo escenario histórico porque en él se cumple, por efecto de la irrupción de la forma de vida totalitaria, la ruptura entre el pasado y el presente. El europeo medio perdió su capacidad de orientarse desde los fondos de su propia experiencia: "La crisis del mundo actual es en primer término política y (...) la famosa 'decadencia de 0ccidente' consiste sobre todo en la declinación de la trinidad romana religión, tradición y autoridad" (EPF, p. 151). Esto no había pasado desde el hundimiento del mundo antiguo y el nacimiento de Europa, forma de vida colectiva que ahora desaparecía de la superficie de la Historia. 
Escribimos al principio, siguiendo a Ricoeur, que Arendt era una "resistente". Quizá donde mejor se advierta el coraje intelectual que, a mi modo de ver, es su virtud fundamental es en un breve texto que acaba de ser traducido al castellano, "Del desierto y los oasis" (D0), y que podriamos describir como una ventana de esperanza abierta sobre el paisaje nihilista. El texto advierte del error de que, puesto que vivimos en el desierto, somos de su hechura; por contra, nuestro desajuste, observa Arendt, revelado por el dolor, prueba que "bajo las condiciones del desierto somos humanos y estamos aún intactos" (D0, p. 100). En consecuencia podemos transformarlo si evitamos las tentaciones más frecuentes durante la travesía: acomodarse, rendirse o desesperarse. Esto puede sonar a puro voluntarismo. Para Arendt el hombre no está inserto en una historia de necesidades. Esa fue la alucinación compartida, generada por el animal laborans, que finalmente condujo al totalitarismo y a la destrucción del mundo. Pero lo que destruye el hombre se puede reconstruir, porque depende de una de las dimensiones específicas de la condición humana: la acción espontánea asociada al discurso. La historia es una trama de narraciones que se puede regenerar en cualquier momento. Para que eso sea posible sólo hay que preservarse de los peligros que acechan al habitante del desierto: ajustarse al desierto, cosa que procuran los psicólogos convenciéndonos de que seamos disciplinados trabajadores/consumidores; sucumbir en una de las tormentas que se desatan en su espacio, es decir, que sobrevenga un movimiento totalitario y que nos transformemos en hombre-masa, o ignorar que hay oasis en el desierto donde se puede descansar ${ }^{35}$.

Que esta idea de que el desierto no había cerrado la posibilidad de recuperar mundo no era un pío deseo lo intentó probar mediante el análisis de la revolución húngara que añadió a la nueva edición de OT. Allí concluía, en 1957, que los húngaros se habian levantado, contra toda lógica histórica, por efecto de las palabras y del coraje de unos pocos. De ese acontecimiento extraía Arendt la siguiente conclusión: "La voz del Este de Europa hablando tan clara y llanamente de libertad y de verdad resonó como una última afirmación de que la naturaleza humana es inalterable, de que el nihilismo será vano, de que el anhelo de libertad y verdad surgirán siempre del corazón y del espíritu del hombre, incluso en ausencia de toda enseñanza y en medio de un adoctrinamiento abrumador" $(R, 128)$.

\section{NOTAS}

1 El siglo XX ha presenciado el fin de la época moderna y el comienzo de "otra" a la que la propia Arendt bautiza con el nombre provisional de "tiempos modernos". Lo moderno no es ya una promesa, una búsqueda, sino la realidad misma, en la medida en que el mundo se estructura como un proceso de producción de "lo nuevo". "La Edad Moderna no es lo mismo que el Mundo Moderno. Cientificamente, la Edad Moderna, que comenzó en el siglo XVII terminó a comienzo del XX; politicamente, el Mundo Moderno, en el que hoy dia vivimos, nació con las primeras explosiones atómicas" ( $\mathrm{CH}$, p. 17). El hoy desde el que escribe Arendt es 1958, fecha de redacción del prólogo a La condición humana. Nuestro propósito es describir el análisis que Arendt hace de la crisis de la modernidad como algo ya resuelto, como un tiempo histórico cerrado por un acontecimiento que al mismo tiempo que efectúa la clausura, lo ilumina y permite su comprensión. Ese acontecimiento es el surgimiento del totalitarismo.

2 Doy por sabida la distinción que vertebra la $\mathrm{CH}$ en las tres modalidades del quehacer humano en labor, trabajo y acción. Cada una de ellas implica un tipo de existencia; si se impone a las otras, conlleva un modo univoco de determinar la realidad. El "animal
Recibido: 12 de enero 2008

Aceptado: 13 de agosto de 2008 
laborans" -Arendt lo llama así porque se trata de una forma de vida no-humana, pues consumir para satisfacer nuestras necesidades vitales es lo que compartimos con los animales- ha ocupado la esfera pública, lo que para Arendt significa precisamente la destrucción de la misma: "El resultado es lo que llamamos con un eufemismo cultura de masas, y su enraizamiento es un infortunio universal que se debe, por un lado al perturbado equilibrio entre labor $y$ consumo y, por el otro, a las persistentes exigencias del animal laborans para alcanzar una felicidad que sólo puede lograrse donde los procesos de agotamiento y regeneración de la vida, del dolor y de librarse de él, encuentren un perfecto equilibrio" $\left(\mathrm{CH}_{\text {, }}\right.$ p. 180). Semejante demanda de felicidad y placer mediante el consumo está condenada al fracaso, pero para Arendt el verdadero problema es que ocupó con sus asuntos el espacio de lo público, y al hacerlo preparó el camino para la llegada de los movimientos totalitarios.

3 Contra las interpretaciones de Arendt como "un pensamiento vuelto al pasado", Ricoeur subraya más bien que es el suyo un "pensamiento resistente en un doble sentido: tanto filosófica como políticamente" (Ricoeur, 1991, p. 5). Wollin le atribuye un "talante anticuarista-homérico" y escribe que "Arendt revela una serie de tendencias normativas antiguas que a menudo no hacen justicia a la naturaleza de la modernidad política" (Wollin, 2003, pp. 117 y 115 respectivamente). También Habermas: Arendt había "tratado de renovar a su manera la pretensión de la política clásica... rehabilitar la visión que aquella filosofía política [del derecho natural] tenía de las cosas, con la vista puesta, eso sí, en un mundo que apenas si se ajusta ya a las viejas categorías" (Habermas, 1984, p. 200).

4 La comprensión es definida por Arendt como una forma especifica del pensar distinta del conocer (como adquirir información), explicar, juzgar o especular: "Es una actividad sin fin, en constante cambio y variación, a través de la cual aceptamos la realidad y nos reconciliamos con ella, es decir, tratamos de estar en casa en el mundo" (EC, p. 371). De la definición se deriva que el término tiene para Arendt, además del alcance epistemológico tradicional, una dimensión práctica que hace de la tarea de comprender una especie de acción teórica que tiene de suyo consecuencias políticas: "la comprensión se vuelve la otra cara de la acción" (EC, p. 391). En una entrevista, a la pregunta de si escribe para influir en los demás, respondió: "Yo quiero comprender. $Y$ si otros comprenden en el mismo sentido en que yo he comprendido, ello me produce una satisfacción personal, como un sentimiento de encontrarme en casa" ["¿Qué queda? Queda la lengua alemana". Entrevista con Günther Gauss (1964) EC, p. 19]. La reconciliación con el mundo heredado del siglo $X X$ arrasado por el totalitarismo, fue probablemente la inspiración que guió la obra toda de Arendt, primero de manera espontánea y luego como un programa perfectamente definido.

5 Véase Eichmann en Jerusalén (EJ, 1967), especialmente el capítulo 6 "La solución final. Matar".

6 La tesis del "mal radical" fue sostenida por Arendt, tomando la expresión de un escrito tardío de Kant, La religión dentro de los límites de la mera razón, por el motivo fundamental de que le parecía que el tamaño del cri- men sobrepasaba la medida humana. Por muy monstruosa que una mente pudiera llegar a ser, no era posible que hubiera deseado y dispuesto los campos de exterminio. Por eso escribió hacia el final de OT, en un tono inequívocamente elegíaco: "Los regímenes totalitarios han descubierto sin saberlo que hay crimenes que los hombres no pueden castigar ni perdonar. Cuando lo imposible es hecho posible se torna en un mal absolutamente incastigable e imperdonable que ya no puede ser comprendido ni explicado por los motivos malignos del interés propio, la sordidez, el resentimiento, el ansia de poder y la cobardía. Por eso la ira no puede vengar; el amor no puede soportar; la amistad no puede perdonar" (OT, p. 556). A este análisis seguia un reconocimiento de la extrema dificultad del concepto, que había escapado al tratamiento de la teología cristiana y a la del mismo Kant, que había reculado, después de darle nombre. Arendt terminaba sugiriendo que las conclusiones que se seguían de este enfoque eran paradójicas pero que en cualquier caso, hay que hablar de mal absoluto cuando estamos ante un sistema político para el que "todos los hombres se han tornado igualmente superfluos" (OT, 557).

7 En las crónicas que mandaba al New Yorker la cuestión no era ya cómo fue posible la solución final sino qué tipo de humano sirvió al aparato burocrático y estuvo en contacto con las víctimas, una vez que se tomó la decisión de exterminar a todo un pueblo. Al observar a Eichmann descubrió que no estaba ante un ser sanguinario -un Gilles de Rais- sino ante un hombre de una absoluta mediocridad. El único rasgo que destacaba era la ausencia de pensar por sí mismo, la carencia de 
juicio: "Eichmann no era estúpido. Únicamente la pura y simple irreflexión -que en modo alguno podemos equiparar con la estupidez- fue lo que le predispuso a convertirse en el mayor criminal de su tiempo" (EJ, 413). Por tanto, Arendt al plantearse elegir entre atribuirle al oficial de las SS una "diabólica profundidad" o una personalidad "vacía" incluso "cómica", optó por lo segundo. La incapacidad de juzgar por cuenta propia acerca de las cosas se convertía ahora en la verdadera causa del mal.

8 La mejor descripción de lo que Arendt quiere decir exactamente con la nada trasparente expresión "banalidad del mal" la da en una de las cartas a Gershom Scholem, quien había acusado a Arendt de dejarse llevar por una expresión ingeniosa: "me suena más a un slogan" (C, 2002, p. 16). Pero Arendt habia reflexionado a fondo y estaba en condiciones de precisar que, a su juicio, "el mal nunca es 'radical', que es sólo extremo, y que no posee ni profundidad ni dimensión demoníaca ninguna" (C, 2002, p. 19). En realidad, Arendt estaba descontenta con su propia conclusión de OT respecto de que el mal totalitario es "radical" y "absoluto" porque sencillamente significaba sacarlo de la esfera de los asuntos humanos y comprometer la exigencia intelectual de abrirse a la teología. Aunque parezca una ironía, el juicio contra Eichmann en Jerusalén, puso en marcha el proceso de reconciliación de Arendt con el mundo, sobre el que venía reflexionando desde que iniciara la serie de ejercicios de reflexión política que fueron apareciendo entre 1954 y 1968. ¿Había destruido el totalitarismo el futuro de Occidente, haciendo imposible la recuperación del espacio público? ¿Podía la comprensión de lo sucedido dar una segunda oportunidad e iniciar otra historia, ahora que comenzábamos a saber que no existe La Historia, sino muchas historias, esto es, muchos comienzos, pero ningún final necesario?

Dejando de lado su función en la evolución del pensamiento de Arendt, la tesis de la banalidad del mal no desacreditaba el sufrimiento del pueblo judío o aliviaba la responsabilidad de los verdugos. Como observa juiciosamente Xavier Antich, la tesis de la banalidad del mal "alerta sobre los demonios que alimentan el fenómeno del totalitarismo; sólo un análisis ingenuo o apresurado podría interpretar esta corrección del diagnóstico [respecto del de OT] en términos de relajación de la crítica o de olvido del sufrimiento de las víctimas" (Antich, 1994, p. 81). En el mismo sentido, Agustín Serrano, en su nota de presentación a su traducción de la correspondencia Arendt/Scholem, invita a mantener separados los respectos lógicos en que se emplea el concepto de "banalidad" aplicado al mal, pues una cosa es referirse a la consistencia propia del mal, sea cual fuere su origen y forma de manifestarse, y otra "no reparar por sistema, por banalidad, en la perpetración del mal y en el sufrimiento de los hombres, sea cual fuere la consistencia última de aquél" (Serrano s/f, p. 27).

9 Es el título del $\S 45$ del capítulo VI y

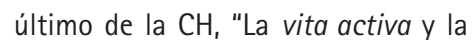
Época moderna".

10 En un coloquio celebrado en torno a su obra, la propia autora reconocía que el principal error de la $\mathrm{CH}$ fue "examinar lo que, según las tradiciones, se denomina vita activa desde el punto de vista de la vita contemplativa, sin decir nada acerca de la vita contemplativa" (AA, p. 142).
11 Arendt atribuye precisamente a la exigencia teórica de justificar la hipótesis de la "banalidad del mal" la redacción de La vida del espíritu: "... después de que me llamara la atención un hecho que, por fuerza, 'me puso en posesión de un concepto' (banalidad del mal), no pude evitar suscitar la quaestio juris y preguntarme 'con qué derecho lo poseía y lo utilizaba'" (VE, p. 16).

12 Como entrada a la segunda parte de su ensayo sobre Benjamin, "Walter Benjamin 1882-1940", "Los tiempos de oscuridad", cita lo siguiente, copiado de una carta del propio Benjamin a Scholem: "Al igual que alguien que se mantiene encima de la nave trepándose a lo más alto de un mástil que se está derrumbando. Pero desde allí, tiene la oportunidad de dar una señal para su rescate" (HTO, p. 180). La imagen proyecta dos de la virtudes que Arendt tenía en más estima y que practicó durante toda su vida: el coraje de resistir luchando y una cierta confianza en que, a pesar de que el horizonte esté cerrado, siempre cabe esperar que se abra un resquicio. De hecho había escrito años antes en un ensayo sobre Kafka: "Sólo la salvación, no la ruina, llega de improviso, pues la salvación y no la ruina depende de la libertad y voluntad de los hombres" (EC, p. 96).

13 El moto que Arendt pone al frente del capitulo VI de la $\mathrm{CH}$ es de Kafka y dice: "Encontró el punto de Arquímedes, pero lo usó contra sí mismo; parece que sólo se le permitió encontrarlo con esta condición" ( $\mathrm{CH}$, p. 325). El apólogo remite a la ciencia moderna que, según Arendt, ha podido llevar a cabo el proceso de dominio de la naturaleza, sólo a partir del momento en que contempló todos los fenómenos naturales como parte de un pro- 
ceso único que los abarca y que, por tanto, son contemplados desde un ojo racional -el sujeto trascendental- situado fuera del cosmos. Pero semejante proceso, al mismo tiempo que una riqueza inesperada ha traído consigo la destrucción del mundo humano en las dos esferas en que se articula: la esfera de lo privado y la de lo público. El problema teórico de Arendt estaba en sustituir el punto de vista de Arquímedes por el punto de vista del náufrago.

14 No hace al caso entrar en las relaciones personales entre Heidegger y Arendt, cosa que se va convirtiendo en una costumbre. Arendt fue muy perspicaz, gracias a que se había convertido en una pensadora conscientemente perspectivista, al comprender que el genio metafísico de Heidegger lo convertía en poco menos que un idiota en política. Asi lo expresó en la alegoría de "Heidegger el zorro" (EC, pp. 435-436) y también en el ensayo que le dedicó con motivo de su ochenta cumpleaños. Alli y partiendo de una reflexión de Heidegger sobre cómo entiende Platón la posición del pensador, dice Arendt: "Cuando les afecta el asombro ante lo sencillo, cuando, cediendo a este asombro, se aventuran en el pensamiento, saben que están desarraigados de su situación propia en el fluir de las ocupaciones y quehaceres en que se llevan a cabo los asuntos humanos" (MH, p. 265). Todo lo que tuvo que decir frente a la marea creciente del nacionalismo centroeuropeo fue que era "el encuentro del hombre moderno con la técnica definida a nivel planetario" (MH, p. 270, nota 1).

15 A Arendt siempre le sorprendió la impotencia de la filosofía para enfrentarse a y rechazar los aconte- cimientos políticos surgidos con el éxito de los sistemas totalitarios nazi y soviético. De hecho fue uno de los puntos de energía que movilizó su pensamiento y que en una ocasión le llevó a escribir: "La hostilidad entre política y filosofía (...) ha sido el azote del arte de gobierno de Occidente, así como de la tradición filosófica desde que los hombres de acción se separaron de los hombres de pensamiento, es decir, desde la muerte de Sócrates" (SR, p. 320, nota 1).

16 Es decir, seguian siendo ilustrados porque seguian siendo idealistas platónicos, aunque hubieran vislumbrado el fondo del callejón sin salida en que habia terminado la filosofía alemana ante la inesperada novedad del totalitarismo: "No estaba claro en absoluto qué tipo de praxis perseguir. Como había advertido Horkheimer en Eclipse of Reason, la racionalidad no suministraba líneas de orientación para la actividad política" (Jay, 1974, p. 449).

17 Durante su exilio en Estados Unidos, la Escuela de Frankfurt no superó la aporía en que cayeron al fundar su crítica a la llustración en la tesis de que el mal residia en el dominio que ejercía los usos de la razón sobre la naturaleza, produciendo la alienación del hombre respecto de ésta, $y$, mantener al mismo tiempo la exigencia de la utopía como emancipación en el final de los tiempos. La praxis revolucionaria resultaba ser una idea demasiado ilustrada. Jay tiene razón cuando, al discutir la posición final de los principales representantes de la escuela, observa que su "objetivo obvio era la reconciliación con la naturaleza, pero nunca se aclaró del todo lo que esto podía significar precisamente" (Jay, 1974 , p. 430).
18 "La acción, única actividad que se da entre los hombres sin el intermedio de cosas o materia, corresponde a la condición humana de la pluralidad". Esta pluralidad funda por así decir la política, la acción más específicamente humana: "puesto que la acción es la actividad política por excelencia, la natalidad y no la mortalidad, puede ser la categoría central del pensamiento político, diferenciado del metafísico" ( $\mathrm{CH}, 19$ y 21).

19 Se entiende mejor cuando recurre al concepto "sentido común" para explicar que es el que permite al yo encerrado en su subjetividad, tener una experiencia común a la de los demás hombres. De ahi que el sentido común ocupe "un alto rango en la jerarquía de las cualidades políticas" y que su desaparición, "cuando se corresponde con un notable incremento de la superstición y de la charlatanería" constituya un indicio "casi infalible de alienación de mundo" (CH, 275).

20 Apud Droysen citado en HI 59.

21 Hobbes vio con más claridad que nadie la nueva tarea que incumbía a la filosofía "era regular propósitos y fines y establecer una teleología razonable de la acción" (EPF, p. 86).

22 De la importancia de Montesquieu para la evolución del pensamiento de Arendt sobre lo político da fe el papel que desempeñan sus ideas en dos decisivos ensayos de Arendt, "Comprensión y política. (Las dificultades de la comprensión)" y "De la naturaleza del totalitarismo. Ensayo de comprensión", ambos de 1953. En este segundo, la definición de gobierno constitucional que propone el filósofo francés en El espíritu de las leyes (1748) le sirve a Arendt de modelo para captar per negationem la esencia del gobierno totalitario. 
Ambos ensayos representan, en el conjunto de su obra, una especie de punto de no retorno en lo que respecta a su esfuerzo por determinar no sólo la esencia del totalitarismo, sino la posibilidad de luchar contra él y vencerlo (Ambos artículos en EC, pp. 371 y ss y 395 y ss).

23 Rousseau comete, frente a Montesquieu, el error de confundir la libertad con la soberania de la voluntad, desactivando así su visión del espacio público como algo irreductiblemente plural, que hay que preservar de la tentación de protegerlo de su inherente contingencia y fragilidad. Arendt, concluye, del lado de Montesquieu, que "si los hombres quieren ser libres deben renunciar precisamente a la soberania" (EPF, 177). Sobre el error consistente en confundir la soberanía con la libertad, véase $\mathrm{CH}$, p. 308.

24 "La causa por la que Platón quería que los filósofos se convirtieran en gobernantes de la ciudad está en el conflicto entre el filósofo y la polis, o en la hostilidad de la polis hacia la filosofía, que quizá se mantuvo latente durante cierto tiempo, antes de mostrarse como una amenaza para la vida del filósofo en el juicio y condena a muerte de Sócrates" (EPF, pp. 117-118).

25 Cf. OT 378: "No el hombre sino Dios debe ser la medida de todas las cosas".

26 Arendt cita a Tocqueville: "Como el pasado ya no ilumina el porvenir, el espíritu humano camina entre tinieblas" (HI 60).

27 Y para Arendt el sentido de la historia sólo puede acogerse en un relato que transfiera la fugacidad del acontecimiento a la duración de un relato bien contado. Sólo de esa manera puede el hombre soñar coherentemente con la inmortalidad.

28 Aunque es muy difícil resumir la idea central de Arendt sobre la acción (política), el siguiente texto alcanza un notable grado de precisión: "Para Arendt libertad y acción son lo mismo o dos aspectos de lo mismo: se es libre en tanto en cuanto se actúa, ni antes ni después. El grado de libertad política de los hombres se mide por la participación de los mismos en el espacio público, por su actuación conjunta, mediante la cual se muestran mutuamente y llevan a cabo acuerdos que establecen reglas del juego que limitan la acción pero, a cambio, otorgan a la comunidad política una estabilidad relativa sin la que no puede mantenerse el espacio de aparición" (Esteban, 2006, p. 76).

29 Patocka ha ayudado a pensar esta hipótesis arendtiana al describir la vida sin libertad, en la rutina de la necesidad y la costumbre, de los humanos que habitaban en los grandes imperios de la antigüedad Cf. Patocka 1988, "El principio de la historia", pp. 47 y ss.

30 El título del parágrafo 35 del capítulo VI "La vita activa y la época moderna" es "La alienación del mundo" (CH 325 y ss).

$31 \mathrm{El}$ moto que pone Arendt al frente de la tercera parte de OT reza: "Los hombres normales no saben que todo es posible". Es cita de David Rousset, autor de Les jours de notre mort (1947), uno de los primeros y más profundos libros sobre los campos de exterminio que se publicaron y en el que Arendt se apoyó para describir la función que los campos de exterminio tenían en el proyecto totalitario de "dominación total" (Cf. OT pp. 533 y ss). Para precisar en qué sentido hay que entender ese "todo es posible": "La falacia trágica de todas esas profecias, originadas en el mundo que todavía era seguro, consistió en suponer que existía algo semejante a una naturaleza establecida para siempre, en identificar a esta naturaleza humana con la Historia y en declarar así que la idea de dominación total era no sólo inhumana, sino también irrealista. Mientras tanto, hemos aprendido que el hombre es tan grande que realmente puede ser lo que quiera ser" (OT, p. 553).

32 Esta remisión de la técnica a sí misma es coincidente con el método de la ciencia moderna que se pregunta por las condiciones de posibilidad universales que valgan para cualquier situación semejante. "La maravilla máxima de la mente humana, la ciencia física, nace de la técnica (...) El nuevo tecnicismo, en efecto, procede exactamente como va a proceder la nuova scienza" (Ortega, 1983, V, p. 372). Cf, CH, p. 387.

33 Recuérdese la importancia que concede Arendt al imperialismo como uno de los factores clave en el proceso de destrucción del mundo liberal-burgués porque entre otras cosas contribuyó a la gestación de los Ilamados "hombres superfluos". Cf. especialmente el cap. VII "Raza y burocracia" OT, pp. 251 y ss.

34 Véase el recorrido por el concepto de totalitarismo, desde sus orígenes en la Italia fascista hasta su decadencia después de la caída del muro de Berlín en 1989 que lleva a cabo Juan Francisco Fuentes en "Totalitarismo: origen y evolución de un concepto clave" (Fuentes, 2006).

35 Aunque no hay espacio para comentarlos en detalle, los oasis son la creación artística, la soledad del filósofo, el amor y la amistad. 


\section{BIBLIOGRAFÍA}

\section{Obras citadas de Hannah Arendt}

OT Los orígenes del totalitarismo (1951) Madrid, Taurus, 1974 (Nueva edición en tres volúmenes en Madrid: Alianza, 1981).

CH La condición humana (1958), BarceIona, Seix Barral, 1974. Hay una reedición con prólogo de Manuel Cruz en Barcelona, Paidós, 1993.

EPF Entre el pasado y el futuro (1961), Barcelona, Península, 1996. Algunos artículos de este libro se han editado en Hannah Arendt: de la historia a la acción, Barcelona, Paidós - I.C.E.U.A.B., 1995.

EJ Eichmann en Jerusalén. Un estudio sobre la banalidad del mal (1963), Barcelona, Lumen, 1967. Hay reedición en la misma editorial, 1999.

SR Sobre la revolución (1965), Madrid, Revista de Occidente, 1967. Reedición en Madrid: Alianza, 1988.

HTO Hombres en tiempos de oscuridad (1968), Barcelona, Gedisa, 1990 (La primera edición no contenía todos los ensayos. La reedición de 2001 incorpora los que faltaban.)
VE La vida del espíritu (1978), Madrid, Centro de Estudios Constitucionales, 1984. Una segunda ed. en Barcelona, Paidós, 2002.

HA De la historia a la acción, Barcelona, Paidós, 1995.

EC Ensayosdecomprensión(1930-1954), Madrid, Caparrós editores, 2005.

MH "Martín Heidegger, octogenario" (1969), Madrid, Revista de Occidente.

C Correspondencia: Hannah Arendt Gershom Scholem (1963), en relación con Eichmann en Jerusalén. Raíces, n. ${ }^{\circ}$ 36, Madrid 2002, pp. 13 y ss. Véase el estudio de acompañamiento de Agustín Serrano de Haro, "Acotaciones a la correspondencia entre G. Scholem y H. Arendt", traductor de la misma.

DO "Del desierto y los oasis" (1955), Revista de Occidente, Madrid, octubre 2006, n. 305, pp. 99-102.

$R \quad$ "Reflexiones sobre la revolución húngara" (1957), Debats, Valencia, 1997, n. ${ }^{\circ} 60$, pp. $118-140$.

\section{Otras referencias}

Antich, X. (1994): "Nuestra desventurada condición de supervivientes", En tor- no a Hannah Arendt (complilación de M. Cruz y F. Birulés), Madrid, Centro de Estudios Constitucionales.

Esteban Enguita, J. E. (2006): "Praxis, poder, libertad", Revista de Occidente, Madrid, octubre, n. ${ }^{\circ} 305$, pp. 69-77.

Fuentes, J. F. (2006): "Totalitarismo: origen y evolución de un concepto clave", Revista de Estudios Políticos, Madrid, n. ${ }^{0} 134$, pp. 195-218.

Habermas, J. (1989): El discurso filosófico de la modernidad, Madrid, Taurus.

Habermas, J. (1984): "Hannah Arendt", en Perfiles filosófico políticos, Madrid, Taurus.

Ortega y Gasset, J. (1983): Obras Completas, doce volúmenes. 1.a edición, Madrid Alianza/Revista de Occidente.

Patočka, J. (1988): Ensayos heréticos, Barcelona, Península.

Ricoeur, P. (1991): "De la filosofía a lo político. Trayectoria del pensamiento de Hannah Arendt", Debats, Valencia, n. ${ }^{\circ} 37$, pp. 4-7.

Young-Bruehl, E. (1993): Hannah Arendt, Valencia: ed. Alfons el Magnanims.

Wolin, R. (2003): "Hannah Arendt: Kultur, 'irreflexión' y envidia de la Polis", en Los hijos de Heidegger, Madrid, Cátedra. 